\title{
Chronotropic response to exercise in patients with atrial fibrillation: relation to functional state
}

Maarten P van den Berg, Harry J G M Crijns, A T Marcel Gosselink, Stan A J van den Broek, Hans J Hillege, Dirk J van Veldhuisen, Kong I Lie

\begin{abstract}
Objective-To determine the relation between functional capacity and heart rate response to exercise in patients with atrial fibrillation.
\end{abstract}

Subjects-73 consecutive patients with chronic atrial fibrillation.

Main outcome measures-Relation between functional capacity, measured as peak oxygen consumption (peak $\nabla_{2}$; $\mathrm{ml} / \mathrm{min} / \mathrm{kg}$ ), and heart rate at all stages of exercise in univariate and multivariate analyses.

Results-Peak $\mathrm{Vo}_{2}$ showed no correlation with resting heart rate, but it showed a negative correlation with heart rate during the first stage of exercise $(r=-0.94$, $p<0.01$ ). Indeed, heart rate during the early stages of exercise (stages 1-5) was higher in patients with a peak $\nabla \mathrm{O}_{2}$ less than or equal to $20 \mathrm{ml} / \mathrm{mm} / \mathrm{kg}$ than in those with a peak $\nabla_{2}$ greater than $20 \mathrm{ml} / \mathrm{min} / \mathrm{kg}$ (heart rate $140 v 125$ beats/ min, $p<0.05$ ). At maximal exercise, however, peak $\nabla \mathrm{O}_{2}$ was positively correlated with heart rate $(r=2 \cdot 15, \quad p<$ 0.0001).

Conclusion-In patients with atrial fibrillation and impaired functional capacity heart rate at low levels of exercise is augmented but maximal heart rate attenuated compared with patients with preserved functional capacity. Excessive heart rate responses to minor exercise may have deleterious effects on left ventricular function and thereby further limit functional capacity.

(Br Heart f 1993;70:150-153)

Department of Cardiology, Thoraxcentre, University Hospital Groningen, Groningen, The Netherlands $M P$ van den Bers H J G M Crijns A T M Gosselink S A J van den Broek H J Hillege D J van Veldhuisen K I Lie

Correspondence to: Dr Kong I Lie, Department of Cardiology, Department of Cardiology Thoraxcentre, Univers PO Box 30.001, 9700 RB Groningen, The Netherlands,

Accepted for publication 22 December 1992

As early as 1924 Blumgart noted that in patients with atrial fibrillation the initial chronotropic response to exercise was often excessive. ${ }^{1}$ Several studies subsequently confirmed this observation. ${ }^{2-4}$

In patients with congestive heart failure the plasma noradrenaline response is augmented at low levels of exercise and attenuated at maximal exercise. ${ }^{56}$ The chronotropic response to exercise shows a similar pattern in such patients, ${ }^{6}$ but these studies were performed only in patients with sinus rhythm.

We evaluated the relation between functional capacity and chronotropic responses to exercise in patients with atrial fibrillation. We analysed heart rate responses during exercise testing in a large group of such patients and used univariate and multivariate analysis to delineate the relation between functional capacity, measured as peak oxygen consumption $\left(\mathrm{VO}_{2}\right)$, and heart rate at all levels of exercise.

\section{Patients and methods}

All consecutive patients with chronic atrial fibrillation who underwent an exercise test with measurement of peak $\mathrm{Vo}_{2}$ between January 1988 and September 1990 were eligible for the study. We excluded tests that had been stopped because of ventricular arrhythmias, a fall in blood pressure, ST segment depression on an electrocardiogram, angina pectoris, or non-cardiac conditions limiting exercise, particularly chronic obstructive lung disease and peripheral vascular disease.

\section{EXERCISE TEST}

All exercise tests were performed on a treadmill (Quinton 55 treadmill, Quinton Instruments, Seattle, Washington) with gradual increases of speed and slope, each stage lasting two minutes, according to a modified Naughton protocol (table 1). ${ }^{7}$ Oxygen consumption, carbon dioxide production, and respiratory exchange ratios were measured continuously during exercise by an automated gas exchange system (Sensormedics system 2900, SensorMedics, Anaheim, California). Values were recorded every 20 seconds with an on line computer assembly (IBM computer systems, Austin, Texas). Peak $\mathrm{V}_{2}$ was defined as oxygen consumption $(\mathrm{ml} / \mathrm{min} / \mathrm{kg})$ at peak exercise, calculated as the mean of the values measured in the last minute of exercise. In accordance with the classification proposed by Weber et al patients

\begin{tabular}{lclc} 
Table 1 & Exercise protocol & \\
\hline Stage & Time (min) & Speed $(\mathrm{km} / \mathrm{h})$ & Slope (\%) \\
\hline 1 & 2 & $1 \cdot 6$ & $0 \cdot 0$ \\
2 & 4 & $2 \cdot 4$ & $0 \cdot 0$ \\
3 & 6 & $3 \cdot 2$ & $0 \cdot 0$ \\
4 & 8 & $3 \cdot 2$ & $3 \cdot 5$ \\
5 & 10 & $3 \cdot 2$ & $7 \cdot 5$ \\
6 & 12 & $3 \cdot 2$ & $10 \cdot 5$ \\
7 & 14 & $4 \cdot 8$ & $7 \cdot 5$ \\
8 & 16 & $4 \cdot 8$ & $10 \cdot 0$ \\
9 & 18 & $4 \cdot 8$ & $12 \cdot 5$ \\
10 & 20 & $4 \cdot 8$ & $15 \cdot 0$ \\
11 & 22 & $5 \cdot 4$ & $14 \cdot 0$ \\
12 & 24 & $5 \cdot 4$ & $16 \cdot 0$ \\
13 & 26 & $5 \cdot 4$ & $18 \cdot 0$ \\
14 & 28 & $5 \cdot 4$ & $20 \cdot 0$ \\
15 & 30 & $5 \cdot 4$ & $22 \cdot 0$ \\
\hline
\end{tabular}


with peak $\mathrm{Vb}_{2}$ greater than $20 \mathrm{ml} / \mathrm{min} / \mathrm{kg}$ and peak $\mathrm{VO}_{2}$ less than or equal to $20 \mathrm{ml} / \mathrm{min} / \mathrm{kg}$ were considered to have normal and impaired functional capacity respectively. ${ }^{8}$ The electrocardiogram was monitored continuously (Marquette Electronics, Milwaukee, Wisconsin). We determined heart rate at the end of all stages of the exercise protocol on 10 second rhythm strips. Heart rate after standing for two minutes on the treadmill before exercise was considered to be the resting heart rate. As part of routine procedures, blood pressure was measured at rest and at maximal exercise.

\section{DATA ANALYSIS}

To evaluate the correlation of peak $\mathrm{VO}_{2}$ with heart rate during exercise we performed stepwise multivariate regression analysis for all stages of the exercise protocol, with heart rate as the dependent variable. Besides peak $\nabla_{2}$, several other variables were introduced in the analysis: age, sex, aetiology of atrial fibrillation (including lone atrial fibrillation), and drug treatment (digoxin, calcium antagonists, $\beta$ blockers, amiodarone, and angiotensin converting enzyme inhibitors). To account for the continuity of heart rate at subsequent stages of exercise heart rate at the preceding stage was also included as a variable.

To illustrate the principal findings of the multivariate analysis chronotropic responses of patients with peak $\mathrm{VO}_{2}$ greater than 20 $\mathrm{ml} / \mathrm{min} / \mathrm{kg}$ and peak $\mathrm{VO}_{2}$ less than or equal to $20 \mathrm{ml} / \mathrm{min} / \mathrm{kg}$ were compared. We calculated mean heart rate from stages 1 to 5 to analyse further the difference in chronotropic response at low levels of exercise, as well as mean heart rate at maximal exercise. Also, the mean number of completed stages of the exercise protocol and the mean rise in systolic blood pressure at maximal exercise were determined in these two subsets of patients. To further delineate the importance of possible differences in adrenergic activation chronotropic responses were compared in patients taking only digoxin or calcium antagonists or both or $\beta$ blockers, confining the analysis to patients with peak $\mathrm{V}_{2}$ less than or equal to $20 \mathrm{ml} / \mathrm{min} / \mathrm{kg}$. Again, mean heart rate from stages 1 to 5 was calculated. Also, clinical characteristics (age, sex, duration and aetiology of atril fibrillation) in these patients were compared. Patients taking amiodarone or angiotensin converting enzyme inhibitors were excluded from both these additional analyses as these drugs show some antiadrenergic properties ${ }^{9-11}$ thus possibly confounding the analyses.

\section{STATISTICAL ANALYSIS}

Stepwise multivariate regression analysis was performed for all stages of exercise to delineate variables independently correlated with heart rate. Univariate analysis was then used for comparison of specific subsets of patients. We performed all analyses using Lotus 123 spreadsheet and the statistical package for the social sciences; $p$ values $<0.05$ were considered to be significant.

\section{Results}

PATIENTS

Peak $\mathrm{Vb}_{2}$ was determined in 85 patients with chronic atrial fibrillation. Twelve patients were excluded because of inadequate exercise tests. Thus, 73 patients were included in the study (40 men and 33 women). Their mean age was 59 (range 29-81). The aetiology of atrial fibrillation was valvar heart disease in 27 patients, coronary artery disease in 10, hypertensive heart disease in 11 , and miscellaneous in 11 (mainly congenital heart disease and idiopathic dilated cardiomyopathy). In 14 patients no structural cardiac disease was apparent (lone atrial fibrillation). The median duration of atrial fibrillation was 28 (SD 63) months. Drug treatment included digoxin (47 patients), calcium antagonists (verapamil and diltiazem) (22), $\beta$ blockers (eight), amiodarone (10), and angiotensin converting enzyme inhibitors (17). Mean peak $\mathrm{V}_{2}$ was $19.0(5.9) \mathrm{ml} / \mathrm{min} / \mathrm{kg}$, ranging from 7.4 to $42 \cdot 2 \mathrm{ml} / \mathrm{min} / \mathrm{kg}$. Accordingly, the number of completed stages of exercise varied considerably: 1 to 14 (mean 8). Mean (SD) resting heart rate and mean maximal heart rate were 103 (22) beats/min and 163 (32) beats/min respectively. Mean systolic blood pressure at rest and with maximal exercise was 136 (19) $\mathrm{mm} \mathrm{Hg}$ and 174 (28) $\mathrm{mm} \mathrm{Hg}$ respectively.

PEAK OXYGEN CONSUMPTION AND HEART RATE Table 2 shows the results of the multivariate analysis. There was no correlation between peak $\mathrm{VO}_{2}$ and resting heart rate. At the first stage of exercise however, there was a significant negative correlation between peak $\mathrm{VO}_{2}$ and heart rate: a low peak value correlated with a high heart rate at stage $1(r=-0.94$, $\mathrm{p}<0.01$ ). In contrast, maximal heart rate was significantly lower in patients with a low peak $\mathrm{V}_{2} \quad(r=2 \cdot 15, \mathrm{p}<0.0001)$. Maximal heart rate was also lower in elderly patients $(r=-0.53, \mathrm{p}<0.01)$. Figure 1 shows the chronotropic responses of 45 patients taking only digoxin or calcium antagonists, or both, comparing 21 patients with peak $\mathrm{VO}_{2} \leq 20$ $\mathrm{ml} / \mathrm{min} / \mathrm{kg}$ and 24 patients with peak $\mathrm{VO}_{2}>20$ $\mathrm{ml} / \mathrm{min} / \mathrm{kg}$. Although resting heart rate was equal (110 (23) beats/min and 109 (25) beats $/ \mathrm{min}$ respectively, $\mathrm{p}>0.05)$, patients with impaired functional capacity (peak $\mathrm{V0}_{2} \leq 20 \mathrm{ml} / \mathrm{min} / \mathrm{kg}$ ) had a higher heart rate at low levels of exercise and a lower heart rate at

Table 2 Stepwise multivariate regression analysisequations showing statistically significant correlations between peak $\mathrm{Vo}_{2}$, clincal characteristics, and heart rate at different stages of exercise. *

\begin{tabular}{lc}
\hline HRrest & $=105-18.8 \times \beta$-blockert $(<0.05 / 0.26)$ \\
HR1 & $43+0.91 \times$ HRrest $(<0.0001 / 0.81)-0.94 \times$ \\
HRmax & $=67+0.85 \times$ peak $\mathrm{VO}_{2}(<0.01 / 0.22)$ \\
& age $(<0.01 / 0.19)+2.15 \times$ peak- $(<0.0001 / 0.59)-0.53 \times$ \\
& $(<0.0001 / 0.39)$
\end{tabular}

Heart rate, beats/min; peak $\mathrm{Vb}_{2}, \mathrm{ml} / \mathrm{min} / \mathrm{kg}$; age, yr; HR, heart rate; HR1, heart rate at stage 1 ; HRmax, heart rate at maximal exercise; HRrest, heart rate at rest; peak $\mathrm{V}_{2}$, peak oxygen mal exercise; *Values in parentheses are $p$ values and beta coefficients respectively. Heart rate at all stages of the exercise protocol correlated positively with heart rate at the preceding stage
(equations not shown). tUsed $=1$, not used $=0$. 


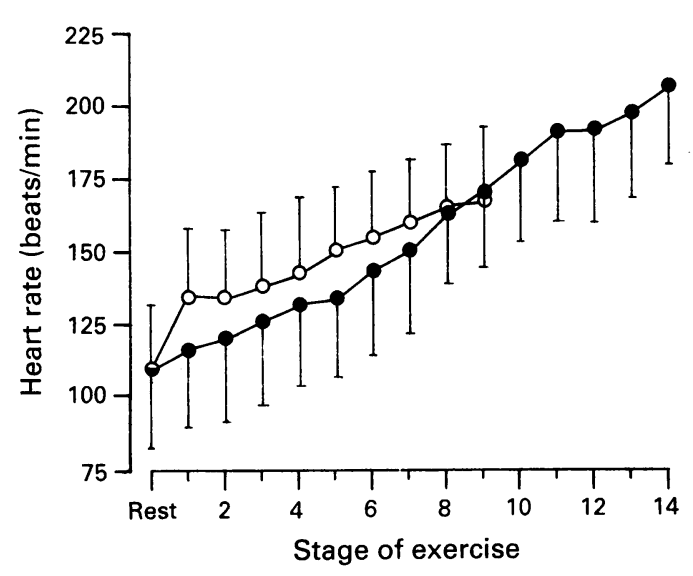

Figure 1 Relation between stage of exercise and heart rate in patients with peak $\dot{V O}_{2}$ greater than $20 \mathrm{ml} / \mathrm{min} / \mathrm{kg}$ (-) and in those with peak $\dot{V} o_{2}$ less than or equal to $20 \mathrm{ml} / \mathrm{min} / \mathrm{kg}$ taking digoxin or calcium antagonists, or both (O-O). Vertical bars show $S D$.

maximal exercise. Mean heart rate at low levels of exercise (stages 1 to 5) was 140 (24) and 125 (27) beats/min respectively ( $\mathrm{p}<$ 0.05 ) and mean heart rate at maximal exercise was 159 (24) and 177 (36) beats/min respectively $(p<0.001)$. Figure 1 also shows that these differences were associated with a noticeable difference in the number of completed stages of exercise. The mean number of completed stages was 7 and 11 respectively $(p<0.001)$. Also the mean rise in systolic blood pressure differed substantially in these two subsets of patients: 31 (21) $\mathrm{mm} \mathrm{Hg}$ and $48(15) \mathrm{mm} \mathrm{Hg}$ respectively $(\mathrm{p}<0.001)$.

DRUG TREATMENT AND HEART RATE

Multivariate analysis showed that only the use of $\beta$ blockers correlated (negatively) with resting heart rate (table 2). In addition, patients with impaired functional capacity (peak $\mathrm{VO}_{2} \leq$ $20 \mathrm{ml} / \mathrm{min} / \mathrm{kg}$ ) taking $\beta$ blockers had a lower heart rate at subsequent (low) levels of exercise than had patients taking digoxin or calcium antagonists, or both (fig 2). Mean heart rate (stages 1 to 5) was 109 (19) and 135 (22) beats/min respectively. Though numbers were small (six and 21 patients respectively), this difference was significant $(p<0.05)$. These subsets of patients were comparable with respect to peak $\mathrm{Vo}_{2}$ and clinical characteristics $(p>0.05)$.

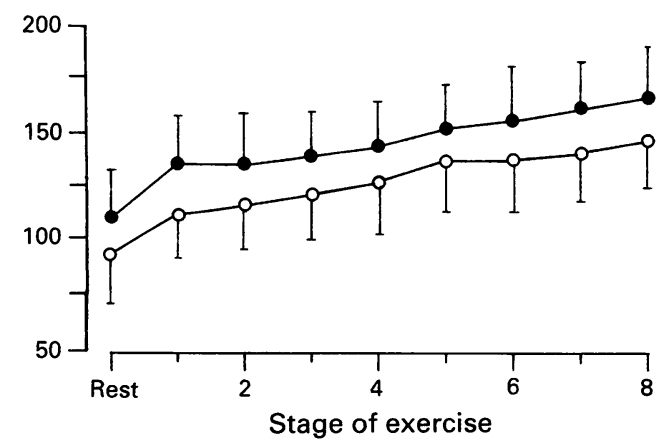

Figure 2 Relation between stage of exercise and heart rate in patients with peak $\mathrm{VO}_{2}$ less than or equal to 20 ml/min/kg taking digoxin or calcium antogonists, or both $(\mathrm{O}-\mathrm{O})$, or $\beta$ blockers $(\mathrm{O}-\mathrm{O})$. Vertical bars show $S D$.

\section{Discussion}

The principal finding of this study is that heart rate at low levels of exercise is augmented and heart rate at maximal exercise attenuated in patients with atrial fibrillation and reduced functional capacity. A relation between impaired functional capacity and nonlinearity of heart rate during exercise in patients with atrial fibrillation was observed previously by Åberg et $a l,{ }^{3}$ but they analysed heart rate at only three different workloads and assessed functional capacity by simply measuring maximally achieved workload. To our knowledge, our study is the first to analyse systematically clinical factors affecting heart rate at low levels of exercise in patients with atrial fibrillation. Factors affecting heart rate with maximal exercise have been studied previously. Atwood et al found that maximal heart rate was higher in patients with lone atrial fibrillation than in patients with known heart disease. Lone atrial fibrillation was also associated with a higher peak $\mathrm{Vo}_{2}{ }^{4}$ Our data show that functional capacity is a more powerful independent predictor of maximal heart rate than is the aetiology of atrial fibrillation. In addition, we found age to be independently predictive of maximal heart rate in patients with atrial fibrillation as it is in patients with sinus rhythm. ${ }^{12}$

\section{CLINICAL RELEVANCE}

Though heart rate at rest (after standing for two minutes on the treadmill before exercise) was controlled, ${ }^{13}$ heart rate exceeded 130 beats/min even at the lowest level of exercise in patients with impaired functional capacity taking only digoxin or calcium antagonists or both. Presumably, comparable heart rates are attained during normal daily activities. Whether tachycardiomyopathy develops under such conditions has never been studied prospectively in humans. Reversibility of tachycardia induced cardiomyopathy is well described, including cardiomyopathy due to atrial fibrillation, with heart rates as low as 120 beats/min. ${ }^{14-16}$ When restoration of sinus rhythm is not feasible in patients with atrial fibrillation, pharmacological treatment with negative dromotropic drugs is aimed at controlling heart rate. In clinical practice dosage of these drugs is titrated on controlling resting heart rate. Though digoxin is reasonably effective in lowering resting heart rate, its value is limited in controlling heart rate even at low levels of exercise. ${ }^{1718}$ The efficacy of calcium antagonists and $\beta$ blockers in controlling heart rate during exercise is comparable, only calcium antagonists (modestly) improving exercise capacity. ${ }^{19-21}$ The relevance of these studies is, however, limited as only patients with (near) normal functional capacity were included and effects on maximal heart rate rather than on heart rate at low levels of exercise were assessed. Our data suggest that $\beta$ blockers may be superior to calcium antagonists and digoxin in controlling heart rate at low levels of exercise in patients with atrial fibrillation and poor functional capacity. A beneficial effect of long 
term $\beta$ blockade on cardiac function was shown in patients with sinus rhythm and dilated cardiomyopathy, ${ }^{22-24}$ but the effect of $\beta$ blockers on functional capacity in patients with atrial fibrillation and poor functional capacity is unknown. "With respect to this clinical issue, angiotensin converting enzyme inhibitors have an interesting pharmocodynamic profile. Improvement of left ventricular function and concomitant correction of abnormal adrenergic stimulation during exercise with angiotensin converting enzyme inhibitors $^{910}$ may increase exercise capacity and also improve heart rate control.

\section{LIMITATION OF THE STUDY}

Our hypothesis was confirmed that in patients with atrial fibrillation and impaired functional capacity the initial heart rate during exercise would be augmented and the maximal heart rate attenuated. However, as noradrenaline concentrations were not measured because of the retrospective design of the study, we were unable to show that these changes in chronotropic response were attributable to similar changes in sympathetic activation during exercise. In this respect, however, the finding that initial heart rate with exercise was not excessive in patients taking $\beta$ blockers is interesting. Obviously, as treatment was not randomised, firm conclusions concerning its specific effects cannot be drawn. Nevertheless, we believe this observation supports our hypothesis. This hypothesis is also favoured by the observed systolic blood pressure responses.

1 Blumgart $H$. The reaction to exercise of the heart affected by auricular fibrillation. Heart 1924;11:49.

2 Hornsten TR, Bruce RA. Effects of atrial fibrillation on exercise performance in patients with cardiac disease. Circulation 1968;37:543-8

3 Åberg H, Strom G, Werner I. Heart rate during exercise in patients with atrial fibrillation. Acta Med Scand 1972;191:315-20.

4 Atwood JE, Meyers J, Sullivan M, Forbes S, Friis R, Pewen $W$, et al. Maximal exercise testing and gas exchange in patients with chronic atrial fibrillation. $\mathcal{f}$ Am Coll Cardiol 1988;11:508-13.

5 Chidsey CA, Harrison DC, Braunwald E. Augmentation of the plasma norepinephrine response to exercise in patients with congestive heart failure. $N \mathrm{Engl} f \mathrm{Med}$
1962;267:650-4

6 Francis GS, Goldsmith SR, Ziesche SM, Cohn JN. Response of plasma norepinephrine and epinephrine to dynamic exercise in patients with congestive heart failure. Am ₹ Cardiol 1982;49:1152-6.

7 Patterson JA, Naughton J, Pietras RJ, Gunner RM. Treadmill exercise in assessment of the functional capacity of patients with cardiac disease. Am 7 Cardiol 1972;30:757-62.

8 Weber KT, Kinasewitz GT, Janicki JS, Fishman AP. Oxygen utilisation during exercise in patients with chronic cardiac failure. Circulation 1982;65:1213-23.

9 Mulligan IP, Fraser AG, Lewis MJ, Henderson AH. Effects of enalapril on myocardial noradranaline overflfects of enalapril on myocardial noradranaline overure. Br Heart $f$ 1989;61:23-8.

10 Corbalan R, Jalil J, Chamorro G, Casanegra P, Valenzuela $P$. Effects of captopril versus milrinone therapy in modulating the adrenergic nervous system response to exercise in congestive heart failure. Am $f$ Cardiol 1990;65:644-9.

11 Kadish AH, Chen R, Schmalz S, Morady F. Magnitude and time course of beta-adrenergic antagonism during oral amiodarone therapy. $\mathcal{F} \mathrm{Am}$ Coll Cardiol 1990;16: $1240-5$.

12 Hammond HK, Froelicher VF. Normal and abnormal heart rate response to exercise. Prog Cardiovasc Dis 1985;27:271-96.

13 Rawles JM. What is meant by a "controlled" ventricular rate in atrial fibrillation? Br Heart f 1990;63:157-61.

14 Philips E, Levine SA. Auricular fibrillation without other evidence of heart disease: a cause of reversible heart failevidence of heart disease: a cause
ure. Am $\mathcal{F}$ Med 1949;7:478-89.

15 Heinz G, Siostrzonek P, Kreiner G, Gossinger H. Improvement in left ventricular systolic function after succesful radiofrequency His bundle ablation for drug succesful radiofrequency His bundle ablation for drug
refractory, chronic atrial fibrillation and recurrent atrial refractory, chronic atrial fibrillation and
flutter. Am $₹$ Cardiol 1992;69:489-92

16 Grogan M, Smith HC, Gersh BJ, Wood DL. Left ventricular dysfunction due to atrial fibrillation in patients initially believed to have idiopathic dilated cardiomyopathy. Am $\mathcal{F}$ Cardiol 1992;69:1570-3.

17 Redfors A. Digoxin dosage and ventricular rate at rest and exercise in patients with atrial fibrillation. Acta Med Scand 1971;190:321-33.

18 Sarter BH, Marchlinski FE. Redefining the role of digoxin in the treatment of atrial fibrillation. Am 7 Cardiol 1992; 69:71-81G.

19 Lundstrom T, Ryden L. Ventricular rate control and exercise performance in chronic atrial fibrillation: effects of diltiazem and verapamil. $\mathcal{f} \mathrm{Am}$ Coll Cardiol 1990;16: 86-90.

20 Lewis RV, McMurray J, McDevitt DG. Effects of atenolol, verapamil, and xamoterol on heart rate and exercise tolerance in digitalised patients with chronic atrial fibrillation. $f$ Cardiovasc Pharmacol 1989;13:1-6.

21 Atwood JE, Sullivan M, Forbes S, Myers J, Pewen W, Olson HG, Froelicher VF. Effect of beta-adrenergic Olson HG, Froelicher VF. Effect of beta-adrenergic
blockade on exercise performance in patients with blockade on exercise performance in patients with
chronic atrial fibrillation. $f$ Am Coll Cardiol 1987; chronic atrial

22 Swedberg K, Hjalmarson A, Waagstein F, Wallentin I. Beneficial effects of long-term beta-blockade in congestive cardiomyopathy. Br Heart $\mathcal{f} 1980 ; 44: 117-33$.

23 Nemanich JW, Veith RC, Abrass IB, Stratton JR. Effects of metoprolol on rest and exercise cardiac function and plasma catecholamines in chronic congestive heart failure secondary to ischemic or idiopathic cardiomyopathy. Am $\mathcal{F}$ Cardiol 1990;66:843-8.

24 Anderson J, Blomstrom-Lundqvist $C$, Hedner $T$, Waagstein F. Exercise hemodynamics and myocardial metabolism during longterm beta-adrenergic blockade in severe heart failure. $\mathfrak{f} \mathrm{Am}$ Coll Cardiol 1991;18: 1059-66. 